\title{
Young children proactively remedy unnoticed accidents
}

\author{
Felix Warneken* \\ Harvard University, Department of Psychology, 33 Kirkland St., Cambridge, MA 02138, United States
}

\section{A R T I C L E I N F O}

\section{Article history:}

Received 2 July 2011

Revised 12 September 2012

Accepted 14 September 2012

Available online 15 October 2012

\section{Keywords:}

Social cognition

Cooperation

Prosociality

Comparative psychology

\begin{abstract}
A B S T R A C T
Human adults will sometimes help without being asked to help, including in situations in which the helpee is oblivious to the problem and thus provides no communicative or behavioral cues that intervention is necessary. Some theoretical models argue that these acts of 'proactive helping' are an important and possibly human-specific form of prosociality. Two experiments examined whether young children proactively help in a situation where an adult did not provide any concurrent behavioral cues that help was needed. Specifically, in Experiment 1 an experimenter either dropped an object without noticing (experimental condition) or on purpose (control). Even though children were bystanders engaged in their own task, they spontaneously intervened by helping instrumentally in the experimental condition in the absence of concurrent behavioral cues from the actor (significantly more often than in the control condition). These acts increased significantly from 21 to 31 months of age, probably reflecting children's emerging social-cognitive capacities to represent goal-directed action. Experiment 2 replicated proactive helping in 2-year-olds in a more closely matched comparison in which in both experimental and control conditions the actor did not notice the accident, and children thus had to infer whether help was needed from the actor's previous responses alone. This result shows that children are able to infer a need for intervention on concurrent situational cues, without behavioral or communicative cues by the helpee. These results indicate that proactive prosociality might be a characteristic of early human ontogeny, emerging in children as young as two years of age.
\end{abstract}

(c) 2012 Elsevier B.V. All rights reserved.

\section{Introduction}

One of the key characteristics of human prosociality is that we literally offer help: we help even when help is unsolicited and we help even when the helpee himself provides no sign that he is in trouble. For example, we might run after a pedestrian who failed to notice that their wallet slipped out of her bag, inform colleagues about new job opportunities, or put a granola bar in our kids' backpack, anticipating that they will become hungry on their school trip. Such examples highlight that humans can recruit fairly sophisticated social-cognitive capacities to identify other people's problems and act prosocially in a flexible

\footnotetext{
* Tel.: +1 617495 3848; fax: +1 6174953903.

E-mail address: warneken@wjh.harvard.edu
}

manner. More specifically, humans engage in what can be called 'proactive prosociality': We act on behalf of others, not only in reaction to overt behavioral or communicative cues by the helpee who is directly soliciting help ('reactive prosociality'), but also in the absence thereof, based upon our knowledge of the situation and the other person's need ('proactive prosociality'; Jaeggi, Burkart, \& van Schaik, 2010; Warneken \& Tomasello, 2008a).

Some theoretical models concerning the evolution of these types of skills argue that proactive prosociality towards non-kin is a special form of prosociality that is human-unique among the great apes (Burkart, Hrdy, \& van Schaik, 2009; Hrdy, 2009; Jaeggi et al., 2010). However, the ontogenetic origins of these behaviors are largely unknown. A number of studies have shown that during the second year of life, children begin to act prosocially in a variety of ways, including acts of helping, comforting, 
and sharing (for reviews see Eisenberg, Fabes, \& Spinrad, 2006; Warneken \& Tomasello, 2009a). However, in all previous studies showing prosocial behaviors in young children, the recipient provided overt cues about the problem, such as reaching for an object (e.g. Dunfield \& Kuhlmeier, 2010; Warneken \& Tomasello, 2006), failing to open something (e.g. Buttelmann, Carpenter, \& Tomasello, 2009; Over \& Carpenter, 2009; Warneken \& Tomasello, 2006), searching for an object (e.g. Liszkowski, Carpenter, Striano, \& Tomasello, 2006), making a negative facial expression of sadness or pain (Bischof-Köhler, 1991; Dunfield, Kuhlmeier, O’Connell, \& Kelley, 2011; Svetlova, Nichols, \& Brownell, 2010), or stating her desire verbally (Brownell, Svetlova, \& Nichols, 2009). These studies also indicate that helping becomes more likely as behavioral and communicative cues are made more explicit, especially when the recipient directly asks for help (Svetlova et al., 2010). However, what remains unknown from these previous studies is whether young children actually must rely on the concurrent behavioral cues of the recipient. That is, do children need these cues to detect that the actor is displeased with the situation and needs help from the child? Alternatively, can they infer that help is needed based upon contextual cues and people's previous behaviors in similar situations? No study has assessed whether young children help proactively in the absence of any concurrent communicative or behavioral cues from the recipient signaling a need for help.

Acts of proactive prosociality are also informative about the underlying motivation for children's prosocial behavior. Specifically, one issue of previous studies has been that even in these situations in which the actor does not directly communicate with the subject, children might interpret behaviors such as reaching for an object or the facial expression of a person who is oriented towards them as a communicative request to help. Thus, it is possible that young children intervene not primarily because of an insight into the person's need and a genuine prosocial motivation to alleviate the other's problem, but because they follow the person's request. Acts of proactive prosociality are thus a diagnostic case to determine whether young children have the motivation to help others in a truly spontaneous fashion.

The current studies tested whether young children will help another person proactively, without any concurrent solicitation or behavioral cues from the actor. These studies examined helping behaviors in children ranging from 21 months old - an age at which children first show helping behaviors towards unfamiliar individuals when they are detached from the parent (Warneken \& Tomasello, $2008 \mathrm{~b})$ - to 30 months old - the age where previous studies have suggested that instrumental helping becomes robust (Svetlova et al., 2010). Children faced a situation in which an accident occurred, but the actor did not notice it, and thus did not make explicit that she had a problem with which she needed help. In particular, in both studies the experimenter was engaged in a task away from the child when an object dropped to the floor. Experiment 1 contrasted an experimental condition, where the actor was turned away and continued with her task without noticing the event, with a control condition in which the actor had discarded the object on purpose. In Experiment 2, the actor did not notice the dropped object in either the experimental or control conditions; rather, only the actor's previous responses to dropped objects differed across conditions. Both studies focused on whether children engaged in 'instrumental helping' by picking up and returning the dropped object. In addition, it was recorded whether children tried to inform the actor about the object on the floor verbally or nonverbally. Children's instrumental helping or informing was never rewarded or acknowledged by the experimenter.

\section{Experiment 1}

\subsection{Method}

\subsubsection{Participants}

We tested a total of $N=72$ children (34 girls and 38 boys), divided into three age-groups of $n=24$ subjects at 22 months $(M=22.2$, range $21-23), 25$ months $(M=24.9$, range 24-26), and 28 months $(M=28.1$, range 26-31), respectively. Sixteen additional subjects were excluded either because of fussiness or because they did not detach from the parent (12), experimenter or equipment error (2) or because they did not meet the criterion of witnessing at least three of the six test events (2). Children were recruited from a child database and lived in the Greater Boston area, typically from middle-class households with parents who had a college education (81\%). Most children (71\%) were described by their parents as white-Caucasian.

\subsubsection{Design}

In a between-subjects design, children were randomly assigned to either an experimental or a control condition ( $n=12$ children per age-group and condition). In the experimental condition, empty cans rolled off a table accidentally without the experimenter noticing. In the control condition, the experimenter discarded the cans on purpose (see procedure for details). Trials were administered in two blocks of three trials each (six trials per session in total). During each block, children played with one of two different distracter toys, counterbalanced across subjects.

\subsubsection{Setup and materials}

All testing was conducted in an experimental room of approximately 6 by 3 meters and video-recorded with remote controlled cameras (see Fig. 1). The first experimenter (E1) stood in front of two tables that were placed against the walls in one corner of the room, her back turned towards the child. During test trials, children were playing with a distracter toy in the center of the room. The distracter toy was either a zig-zag ramp $(50 \mathrm{~cm}$ high and $55 \mathrm{~cm}$ wide) where children could let balls roll down ramps or a jingle-box $(30 \times 30 \mathrm{~cm})$ where children could throw a cube through an opening at the top which would then slide down a xylophone on the inside and reappear through an opening at the bottom. One distracter toy was used for three consecutive test trials and then switched for the remaining three trials (order 


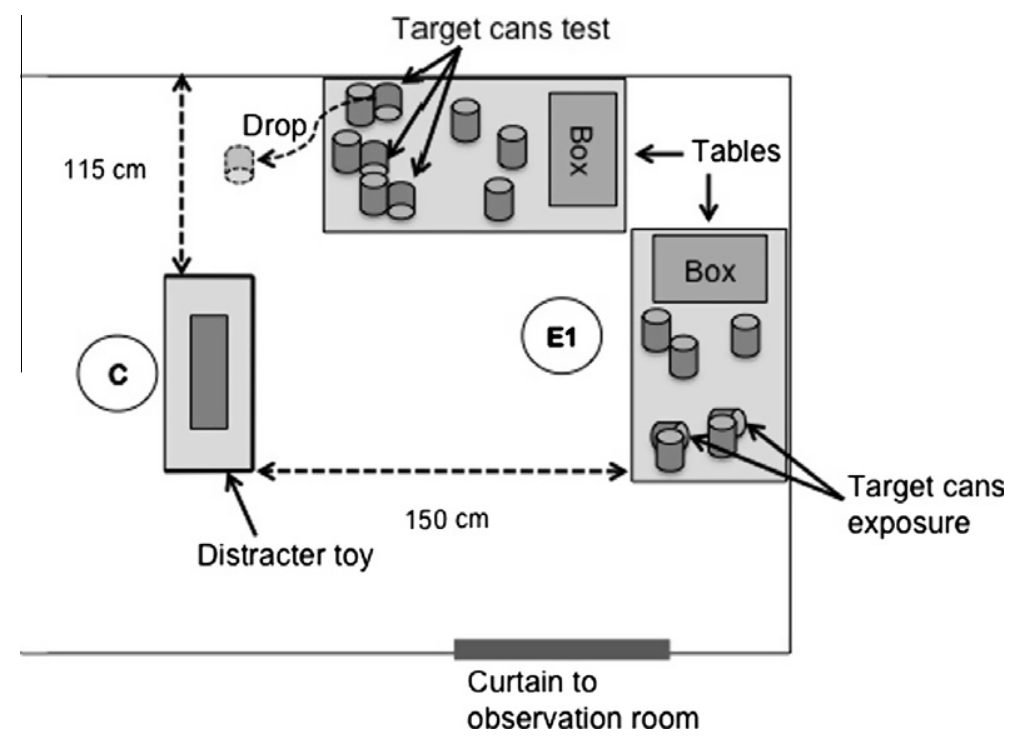

Fig. 1. Schematic drawing of setup for Experiment 1.

counterbalanced between subjects). The target objects were empty milk cans $(6 \times 6.5 \mathrm{~cm})$.

A second experimenter (E2) and the parent were seated in an observation room. E2 exchanged distracter toys and set up additional cans on the tables between trial blocks and otherwise remained in the observation room. Parents remained in the observation room throughout the session, where they could monitor the session over a video screen. An opaque curtain separated the testing room from the observation room, so that while children could not see their parents during the test, they could easily go to their parent at any point. In a few cases $(n=7)$, children seemed uncomfortable without their parent, in which case the parent sat in the back of the room approximately $2 \mathrm{~m}$ behind the child and was turned away reading a magazine.

\subsubsection{Procedure}

During a warm-up in a waiting area, E1 played with the child and showed one of the empty milk cans that would later be the target object during the test. After approximately $5 \mathrm{~min}$, children were brought into the experimental room. To accustom children to the room, they were first given the opportunity to play with the 'jingle box game', which consists of throwing toy cubes through a hole into the box which makes a jingle sound. Toy cubes were scattered across the room so that we could assess whether children felt comfortable moving around in the room. Subsequently, we introduced a short social initiation test to ensure that the child felt comfortable approaching E1 while she was immersed in her work. Specifically, E2 entered the room with a toy while E1 was turned away from the child towards the tables. After a brief play period, E2 encouraged the child to show the toy to E1 by just telling the child to show it to E1. Pilot tests indicated that children younger than 2 years of age had problems with this verbal instruction, and for these children, E2 first showed one toy to E1 herself and then encouraged the child to do the same with another toy. Overall, $78 \%$ or 56 of 72 children passed this social initiation test, with equal numbers of children in both conditions and no effect of age.

Subsequently, the child was playing with a distracter toy, while E1 announced that she had to clean up all the cans that were on the tables. She started to put away the cans in two large cardboard boxes on one of the tables.

The main test was divided into two phases, an exposure phase and multiple subsequent test trials: During the exposure phase, there were two events in which in the experimental condition, a can rolled from the table and dropped on the floor in full view right next to E1. She noticed the accident, exclaiming "Oh no, my can fell!", immediately reaching for the can, picking it up and putting it into the box. In the control condition, E1 intentionally swiped a can off the table ("I don't need those, there you go.") and did not pick it up.

After this exposure phase, children were tested in a first block of three test trials. In the experimental condition, E1 picked up cans from the table while without her noticing, one can rolled from the table, landing in the 'drop zone' next to the child on the left, approximately $1 \mathrm{~m}$ away from the distracter toy. E1 continued to pick up other cans from the table and put them away, without interrupting her work, and thus did not provide any behavioral cues about a problem having occurred. In test trials of the control condition, E1 intentionally rolled a can down the table and looked at it as it fell on the floor in the 'drop zone' next to the child, then turned back towards the table and continued her work just as in the experimental condition. This condition controlled for the possibility that children would return cans to the table irrespective of the experimenter's goal.

After the first block of three trials, E1 took the can-filled box and placed it on a shelf in the back of the room. If cans were still on the floor after the experimental condition, she looked surprised, placing her box on the table and picking 
up the remaining ones as during the introduction phase. In the control condition, E2 cleaned off the floor while the child was distracted by E1. In between blocks, E2 brought in a new distracter toy and set up cans on the tables for the next block while E1 showed the child how to play with the new distracter toy. E1 then returned to her tables and started another block of two exposure and three test trials administered in the same way as in block 1 .

E2 monitored via video whether children had actually witnessed the events during the exposure and the test trials. Children had to meet the criterion of witnessing at least one of the two exposure trials in a given block to proceed. Only one child needed a repetition in block 1 and three children in block 2 .

Trials lasted $15 \mathrm{~s}$. E1 never acknowledged the child's help or attempts to communicate, only picking up the can from the table or taking it just like any other can that was on the table.

\subsubsection{Coding and preliminary analyses}

Coding was done from digital video, with test trials parsed into coding events so that research assistants who were unaware of the hypothesis coded behaviors blind to condition. A second rater coded $20 \%$ of randomly selected videos. The main measure was whether children picked up the can and either put it on one of the tables or handed it directly to the experimenter ('instrumental helping'; $\kappa=1)$. We also coded if children tried to alert the experimenter verbally with utterances such as "The can!" "It fell again!" $(\kappa=.90)$ or nonverbally by looking towards the experimenter and pointing to the can $(\kappa=1)$. For analyses, we collapsed nonverbal and verbal communication into the category "informing". To assess whether children had actually witnessed the dropping of the can in a given trial, we coded whether they either looked in the experimenter's direction during the drop or looked up immediately after the can hit the floor $(\kappa=.88)$.

For the test trials, we set as criterion that children had to witness at least three of the six test events over the session. Two children were not included in the final sample because they witnessed less than three events. In the final sample $(N=72)$, children witnessed the test event in $M=88 \%$ of trials, with no effect of condition or age. We aborted trials in which children walked towards the curtain to their parent or did not engage with the distracter toy ( $M=17 \%$ of trials, with no effect of condition or age). Thus, analyses are based upon trials in which children completed the trial and witnessed the test event, on average $M=4.9$ of the six test trials ( $S E=.13$; range $3-6$ ) per child.

Nonparametric statistics were used as the data were not normally distributed. The main dependent measure instrumental helping had a skewness of 1.59 (SE = .28) and instrumental helping and informing had a skewness of 1.17 $(S E=.28)$. Preliminary analyses showed that there was no effect of gender, order of distracter toys, the first versus second block of test trials, or the behavior during the initiation test on any of the dependent measures. Analyses were thus collapsed across these variables.

\subsection{Results of Experiment 1}

The main question was whether children engage in proactive instrumental helping. This is illustrated in Fig. 1, with dark grey bars representing the mean percentage of trials with instrumental helping as the target behavior, broken down by condition and with age displayed as tertiles for ease of presentation. There was a significant effect of condition, Mann-Whitney $U(N=72)=343.5, p<.001$, with a significant correlation of age in months and helping in the experimental condition, $r_{\mathrm{s}}(n=36)=.41, p<.05$, but not the control condition, $r_{\mathrm{s}}(n=36)=-.16, p=.36$. Comparisons of conditions for each age group separately ( $n=24$ per age-group) showed that there was no difference between conditions in the youngest children at 22 months, $U=54.0, p=.14$, whereas there was a difference between conditions in both older age-groups, 25-month-olds, $U=41.0, p<.05$, 28-month-olds, $U=18.0, p<.001$. Thus, these analyses show that overall, children were more likely to perform the target behaviors in the experimental condition than the control condition, and that this difference emerged with age, with children starting to perform proactive helping consistently around their second birthday.

Interestingly, we observed that children frequently tried to inform the experimenter about the problem by either verbalizing (e.g. "The can fell!", "Another one!") or looking at the actor and pointing at the can. Although prosociality was operationalized as instrumental helping, these communicative acts are interesting for two reasons. First, they could be interpreted as less costly attempts to help by highlighting the unnoticed accident to the experimenter. Therefore, we included both instrumental helping and informing into a measure of overall prosocial behavior. There was again a significant difference between conditions, $U(N=72)=290.0, p<.001$, with a correlation of age and prosocial behavior in the experimental condition, $r_{\mathrm{s}}(n=36)=.41, p<.05$, but not the control condition, $r_{\mathrm{s}}$ $(n=36)=-.14, p=.42$. Broken down into age-groups ( $n=24$ for each), results showed no effect of condition for 22-month-olds, $U=54.0, p=.14$, but for both older age-groups, 25-month-olds, $U=29.0, \quad p<.01$ and 28 month-olds, $U=12.0, p=.001$. Second, the combination of instrumental helping and communicative attempts highlights the richness of the current behavior, namely that children did not just blindly pick up objects, but were actually trying to help the actor with her problem. Therefore, we computed in how many trials children helped instrumentally and produced a communicative act in addition. As can be seen in Fig. 2, instrumental helping acts were frequently accompanied by communicative attempts. These instances never occurred in the control condition. This provides evidence that children did not just pick up objects, but produced a rich set of behaviors aimed at helping the experimenter with the problem. Moreover, it indicates that children were not just copying the experimenter's behavior of picking up cans, but show insight into the situation by intervening in different ways to remedy the other person's situation.

Last but not least, we looked at the results on the level of the individual: How common was instrumental helping 


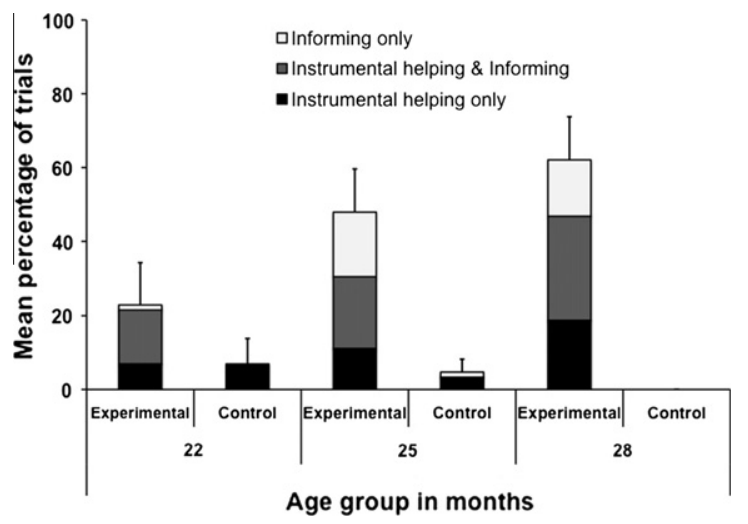

Fig. 2. Mean percentage of trials with proactive prosocial behavior divided into instrumental helping (black) and informing (white), and trials in which children both informed and helped (grey) as a function of age-group and condition. Error bars denote standard errors of mean percentage of total prosocial behavior.

and informing across children? At the three age-groups of 22,25 , and 28 months, 33\%, 50\% and $75 \%$ of children, respectively, performed at least one instrumental helping act during the experimental condition. And when we included cases of informing, 33\%, 67\% and $83 \%$ of children per age-group did so. Thus, few of the 22-month-olds intervened, but around half of the two-year-olds and the vast majority of 2.5-year-olds displayed acts of proactive prosociality.

\subsection{Discussion of Experiment 1}

These results suggest that children are able to help without concurrent cues from the experimenter that she needs help. Specifically, in the experimental condition children frequently returned the dropped can even though the experimenter had not noticed the accident. The control condition rules out the possibility that children generally like to pick up and return dropped objects, for example because they want to engage socially with the experimenter, or because they want her to repeat the action. However, while cues from the experimenter to solicit help were absent in the test phase of the experimental condition, there were overt cues from the experimenter in the test phase of the control condition signaling that the dropping event was done intentionally. It is thus possible that overt cues are not necessary to elicit helping (as demonstrated in the experimental condition), but overt cues are necessary to suppress helping (explaining the low rate in the control condition). Taken together, the difference between conditions could thus be due to the concurrent cues that were provided in the control condition.

To address this issue, we conducted a second experiment in which conditions were more closely matched. In Experiment 2, the difference was only in the exposure phase, where the target can always rolled off the table accidentally, and the experimenter either did (experimental condition) or did not (control condition) pick it up. Importantly, the subsequent block of test events was exactly the same in both conditions, with the experimenter never noticing that cans fell. Thus, in both conditions the adult provided no concurrent cues about the accident. The only difference was how she had previously responded to this type of event; that is, the child had to infer what the experimenter's current goal might be given their past behavior. Because the purpose of this follow-up experiment was to assess the alternative interpretation that concurrent cues in the control condition of Experiment 1 might have accounted for the difference between conditions, we limited our new sample to the age-range that had shown a reliable differentiation in the first study.

\section{Experiment 2}

\subsection{Method}

\subsubsection{Participants}

We tested a total of $N=36$ children (17 girls and 19 boys), divided into two age-groups of $n=19$ subjects at 25 months $(M=25.6$, range $24-26)$, and $n=17$ subjects at 28 months $(M=28.4$, range 27-29), respectively. None of them had participated in the previous or any other helping study. Ten additional subjects were excluded either because of fussiness or because they did not detach from the parent, and one child did not meet the criterion of witnessing at least three of the six test events. Children were recruited from the same child database as those from Experiment 2, typically from middle-class households (91\% of parents with a college education). Most children (78\%) were described by their parents as white-Caucasian.

\subsubsection{Design and procedure}

These were the same as in Experiment 1, with the modification that the experimental and control conditions were more closely matched and differed only during the exposure phase. Specifically, during the exposure phase, there were two events in which in the experimental condition, a can rolled from the table and dropped on the floor in full view right next to $\mathrm{E} 1$, and as in Experiment 1, she exclaimed "Oh no, my can fell!" and picked it up. In the new control condition, the same accident occurred during the exposure phase, but E1 looked at it and said, "I do not need that one." and did not pick it up.

We introduced another modification to Experiment 1 to make the situation more plausible that E1 accidentally caused cans to roll off the table without noticing it. To achieve this, there were sheets of folded paper and cans scattered on the tables. The target cans were placed on their sides, and the folded paper prevented them from rolling off the table. When E1 now removed the paper, the can lost its blockage and slowly started to roll off. This way E1 never actively caused the can to roll off, but this accident occurred as a side-effect of her actions.

\subsubsection{Coding and preliminary analyses}

The coding categories and coding procedure were the same as in Experiment 1. Interrater reliability was again high: instrumental helping $(\kappa=1)$, nonverbal communication $(\kappa=.77)$, verbal communication $(\kappa=.91)$, and gaze $(\kappa=.80)$. Overall, $92 \%$ or 33 of 36 children passed the social 
initiation test. In three cases the parent was in the room facing away from the action and was in a different room in all other cases. As in Experiment 1, nonparametric statistics were used because the data were not normally distributed, with instrumental helping having a skewness of .94 $(S E=.39)$ and the combined prosocial score instrumental helping and informing with a skewness of .54 $(S E=.39)$. Preliminary analyses showed that there was no effect of gender, order of distracter toys, or the first versus second block of test trials.

\subsection{Results and discussion of Experiment 2}

As shown in Fig. 3, children were once again more likely to perform acts of instrumental helping in the experimental condition as compared to the new control condition, Mann-Whitney $U(N=36)=41.0, p<.001$. This was apparent when comparing conditions separately by age-group, 25 -month-olds, $U(n=19)=17.5, p<.01,28$-month-olds, $U(n=17)=4.0, p<.01$. The same results were obtained when instrumental helping and informing were combined into a single measure of proactive prosociality. Children were more likely to perform this behavior in the experimental than the new control condition, both across age-groups, $U(N=36)=30.5, \mathrm{p}<.001$, and separately by age-group, 25-month-olds, $U \quad(n=19)=12.0, \quad p<.01$, 28 -month-olds, $U(n=17)=4.5, p<.01)$. As shown in Fig. 3, children frequently combined informing and instrumental helping within a given trial. This never occurred in the control condition. Thus, once again, children often used a combination of helping and informing which highlights that they were trying to help the actor with the problem and did not just blindly pick up cans.

On an individual level, $67 \%$ of 25 -month-olds and $89 \%$ of 28-month-olds performed at least one instrumental helping act during the experimental condition. When we included cases of informing, $78 \%$ of 25 -month-olds and all 28-month-olds at least once helped instrumentally or through informing. This result thus replicates our finding

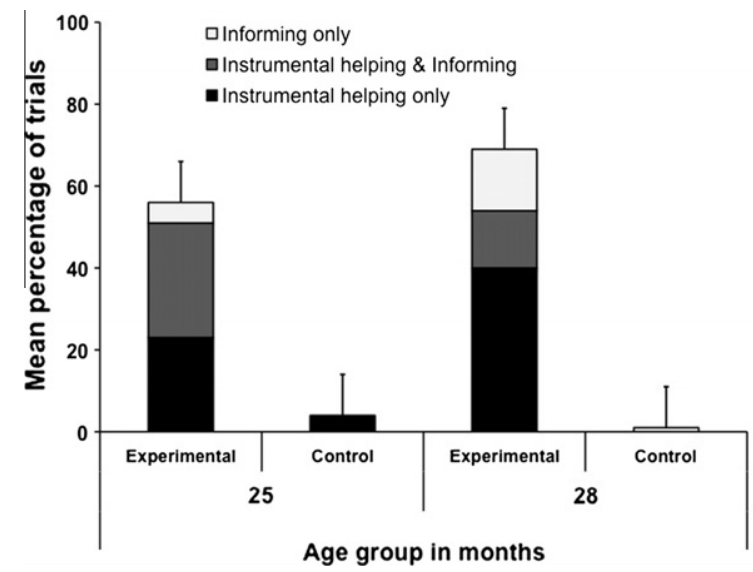

Fig. 3. Mean percentage of trials with proactive prosocial behavior divided into instrumental helping (black), informing (white), and trials in which children both informed and helped (grey) as a function of agegroup and condition. Error bars denote standard errors of mean percentage of total prosocial behavior. from Experiment 1 that proactive helping is common among 2-year-olds. Taken together, Experiment 2 therefore indicates that 2-year-olds help consistently even in the absence of overt concurrent cues from the experimenter.

\section{General discussion}

The current results provide insight into the emergence of proactive helping in young children. Young children take action to intervene on another person's behalf in the absence of any behavioral cues expressing a need for intervention, as well as in the absence of any behavior that could be interpreted as a communicative request for help. They do so without being prompted from the helpee or a parent (who were absent throughout the study), being bystanders involved in their own individual activity, which they have to interrupt in order to help. Results showed a strong age-effect, indicating that proactive helping emerges around the second year of life, with toddlers 21-23 months helping only rarely and children from around 24 months onwards helping frequently by lending a hand or informing the agent about the mishap. A second experiment replicated the main finding that 2-year-olds help proactively, using a more closely matched control condition ruling out that children relied on concurrent cues when inferring whether help was needed or not.

Young children are thus able to utilize fairly sophisticated social-cognitive capacities for prosocial behavior. Specifically, these results show that although facilitative, concurrent behavioral cues are not always necessary for children to intervene in these types of instrumental helping contexts. Previous research has demonstrated that the more explicit the behavioral cues by the agent, the more likely children are to intervene, with toddlers being much more likely to help when being addressed than when the experimenter is just expressing sadness or puzzlement about a displaced object (Svetlova et al., 2010). In the current study, however, children could not rely on the experimenter's behavior after the accident (such as facial expressions or failures to act towards a goal). They thus appear to have been able to infer that help was needed based upon the experimenter's behavior in prior situations, as well as from the situational context of the test event itself. That is, the current results indicate that children do help proactively, not only in reaction to the other person's behavioral expression of need or their solicitation of help.

Moreover, this result rules out the hypothesis that children help only when they are directly addressed, or when they interpret an actor's behavioral expressions as requests for help. In the current study, children were bystanders engaged in their own activity. Nonetheless, results indicated that the children took action to remedy the adult's (unnoticed) accident, even though they could have continued with their game. This suggests that the children's prosocial motivations were strong enough to overcome their attraction to their own activity, even though the adult had not realized something had gone awry. This indicates that even young children are motivated to help spontaneously, without being prompted or cued by another person. Young children's instrumental helping behaviors therefore 
do not necessarily depend on direct communication or nonverbal expressions that could be interpreted as more subtle requests for help.

The findings from these two experiments - which focus on children's understanding of other people's action-problems - complement other research focusing on children's reaction towards people's affective states. First, children as young as 18 months of age show concern (as measured by their facial expression), even if the victim herself displays no emotion after a hurtful act (Vaish, Carpenter, \& Tomasello, 2009). It has been suggested that in these contexts children can sympathize with others through some form of affective perspective-taking based upon situational cues, potentially drawing upon similar experiences in the past (Harris, 2008; Hoffman, 2000; Knafo, Steinberg, \& Goldner, 2011; Vaish et al., 2009). Therefore, the current study indicates that children are able to make determinations in the context of goal-directed action, inferring from the situation that the other's goal is not met. Secondly, the current study adds to these findings about affective perspective-taking in that children not only detect the other person's problem (such as responding with concern or representing events as accidents), but proactively intervene on the other's behalf to change the current situation that causes the other's negative psychological state. Thus, children's ability to represent the other person's problem leads to truly self-initiated prosocial behavior.

One noticeable aspect of the results is that children showed a steep developmental increase in their tendency to help proactively around two years of age. What social-cognitive factors might have contributed to the ontogenetic emergence of such prosocial behavior? One possibility is that this reflects a gradual increase in prosocial motivation. However, research with children as young as 14 months of age has shown that when the other person's problem is made explicit and the type of intervention is easy (such as handing over an object an adult is unsuccessfully reaching for), infants help consistently. When the tasks are more complex - such as helping to retrieve an object from a novel box that the helpee fails to open because he uses the wrong means or helping with a task in which the intended outcome is never actually observed the same children fail to help (Warneken \& Tomasello, 2007). Moreover, the study by Svetlova and colleagues, which systematically varied the kind of cues that the helpee provided, found that the tendency to help is strongly associated with the explicitness of the recipient's cue (Svetlova et al., 2010). These studies indicate that as long as the task demands are low, even young children are willing to help. That is, although a developmental increase in prosocial motivation is possible, it is implausible that motivational factors alone could explain why children become able to help competently in increasingly more complex problem situations.

Rather, the current results suggest that children's ability to help increases as they become better at representing goal-directed action from more subtle situational cues. For example, together with the findings by Svetlova and colleagues, the current evidence indicates that toddlers younger than 2 years help only after explicit concurrent behavioral or communicative cues from the helpee. Fur- thermore, the current study suggests that older children are not only better at reading more subtle communicative and concurrent cues, but that they are even able to help proactively in the absence of these cues in the immediate situation. It thus appears that children's emerging cognitive, and especially social-cognitive skills underlie the increase in helping in early childhood. It remains an open question which skills in particular contribute to this developmental shift. Specifically, children's increase in proactive helping could be the outcome of a gradual improvement of general cognitive processing or greater experience with observing and performing goal-directed actions in particular. It is also possible that the age-difference is related to the finding that 2-year-olds begin to evaluate states in the world as deviating from what ought to be the case (Kagan, 1981). The developmental increase of helping in the current task might also be related to children's improved visual perspective-taking skills, with children at 24 months of age starting to differentiate between objects that another person can or cannot see while they are all visible to the child (Moll \& Tomasello, 2006). Future research should therefore assess how proactive helping is associated with the development of other (social-)cognitive skills to determine which factors account for this developmental emergence.

Another question for future research concerns individual and cultural differences in the expression of these behaviors. The current study as well as a growing body of work on instrumental helping shows that usually the vast majority of children tested perform basic helping behaviors (Warneken \& Tomasello, 2009b). Moreover, the age of onset of instrumental helping in the second year has been replicated across studies and found to be consistent across three different cultural communities in India, Peru and Canada (Callaghan et al., 2011). However, other prosocial behaviors (such as comforting others) do show some cross-cultural variation in toddlers (Kärtner, Keller, \& Chaudhary, 2010). Thus, it remains an open question to what extent social and cultural factors might have differential effects on the development of proactive helping in particular. One possibility is that children who are involved in chores early in life show a steeper increase in this behavior, especially in subsistence societies where adults rely on help from juveniles for everyday tasks (Kramer, 2005). Thus, cross-cultural studies are needed to evaluate whether proactive prosociality is a common trait of early ontogeny, and how cultural factors contribute to the emergence of proactive prosociality in childhood.

Finally, the current results bear on currently debated issues concerning the evolution of human prosociality. Some theorists have proposed that proactive forms of prosociality are an integral part of human social interaction, and moreover that this type of prosociality is unique to the human species among the great apes (Burkart et al., 2009; Hrdy, 2009; Jaeggi et al., 2010). Specifically, chimpanzees on occasion help individuals who solicit help directly through communication or signal a need for help behaviorally, but rarely help when the recipient remains passive and provides no direct cues (see e.g. Melis et al., 2011; Yamamoto, Humle, \& Tanaka, 2009). It has thus been argued that one major difference between humans and 
other apes lies in the cognitive capacity to infer other's goals, enabling humans to act prosocially in a larger variety of contexts and with greater flexibility (Warneken \& Tomasello, 2009a). The current results provide the first experimental evidence that children use their ability to infer other's goals in the absence of overt cues to help others who do not even know they need such help. This is different from previous findings with chimpanzees that emphasize the importance of direct cues from the helpee in promoting such behavior (Melis et al., 2011). Therefore, the currently available evidence hints at an important species-difference, with proactive helping as a potentially human-specific form of prosociality which emerges early in ontogeny.

\section{Acknowledgments}

Thank you to the children and their parents for their participation. Thanks to all members of the Social Cognitive Development Group for their help in conducting the study, especially Nicole Grifka, Lauren Kleutsch, and Kerrie Pieloch. Thanks to Alexandra Rosati, Colin Bannard, Paul Harris, Susan Carey as well as three anonymous reviewers for helpful comments. The research received support from the Science of Generosity Initiative.

\section{References}

Bischof-Köhler, D. (1991). The development of empathy in infants. In M. E. Lamb \& H. Keller (Eds.), Infant development: Perspectives from German speaking countries (pp. 245-273). Hillsdale, NJ: Lawrence Erlbaum Associates.

Brownell, C., Svetlova, M., \& Nichols, S. (2009). To share or not to share: When do toddlers respond to another's needs? Infancy, 14(1), 117-130.

Burkart, J. M., Hrdy, S. B., \& van Schaik, C. P. (2009). Cooperative breeding and human cognitive evolution. Evolutionary Anthropology, 18, 175-186.

Buttelmann, D., Carpenter, M., \& Tomasello, M. (2009). Eighteen-monthold infants show false belief understanding in an active helping paradigm. Cognition, 112, 337-342.

Callaghan, T., Moll, H., Rakoczy, H., Warneken, F., Liszkowski, U., Behne, T., et al. (2011). Early social cognition in three cultural contexts. Monographs of the Society for Research in Child Development, 76(2), vii-142.

Dunfield, K. A., \& Kuhlmeier, V. A. (2010). Intention mediated selective helping in human infants. Psychological Science, 21, 523-527.

Dunfield, K. A., Kuhlmeier, V. A., O’Connell, L., \& Kelley, E. (2011) Examining the diversity of prosocial behavior: helping, sharing, and comforting in infancy. Infancy, 16(3), 227-247.

Eisenberg, N., Fabes, R. A., \& Spinrad, T. (2006). Prosocial development. In N. Eisenberg (Ed.). Handbook of child psychology: social, emotional, and personality development (Vol. 3, 6th ed., pp. 646-718). Hoboken, NJ: John Wiley \& Sons.

Harris, P. L. (2008). Children's understanding of emotion. In M. Lewis, J. M. Haviland-Jones, \& L. F. Barrett (Eds.), Handbook of emotions (3 ed., pp. 320-331). New York: Guildford Press.

Hoffman, M. L. (2000). Empathy and moral development: Implications for caring and justice. New York, NY: Cambridge University Press.

Hrdy, S. B. (2009). Mothers and others: The evolutionary origins of mutual understanding. Cambridge: Harvard University Press.

Jaeggi, A. V., Burkart, J. M., \& van Schaik, C. P. (2010). On the psychology of cooperation in humans and other primates: combining the natural history and experimental evidence of prosociality. Philosophical Transactions of the Royal Society, 365, 2723-2735.

Kagan, J. (1981). The second year: The emergence of self-awareness. Cambridge, Mass: Harvard University Press.

Kärtner, J., Keller, H., \& Chaudhary, N. (2010). Cognitive and social influences on early prosocial behavior in two sociocultural contexts. Developmental Psychology, 46(4), 905-914.

Knafo, A., Steinberg, T., \& Goldner, I. (2011). Children's low affective perspective-taking ability is associated with low self-initiated prosociality. Emotion, 11, 194-198.

Kramer, K. L. (2005). Children's help and the pace of reproduction: Cooperative breeding in humans. Evolutionary Anthropology: Issues, News, and Reviews, 14(6), 224-237.

Liszkowski, U., Carpenter, M., Striano, T., \& Tomasello, M. (2006). Twelveand 18-month-olds point to provide information for others. Journal of Cognition and Development, 7(2), 173-187.

Melis, A. P., Warneken, F., Jensen, K., Schneider, A. C., Call, J., \& Tomasello, M. (2011). Chimpanzees help conspecifics obtain food and non-food items. Proceedings of the Royal Society B, 278(1710), 1405-1413.

Moll, H., \& Tomasello, M. (2006). Level 1 perspective-taking at 24 months of age. British Journal of Developmental Psychology, 24(3), 603-613.

Over, H., \& Carpenter, M. (2009). Eighteen-month-old infants show increased helping following priming with affiliation. Psychological Science, 20, 1189-1193.

Svetlova, M., Nichols, S. R., \& Brownell, C. A. (2010). Toddlers' prosocial behavior: From instrumental to empathic to altruistic helping. Child Development, 81(6), 1814-1827.

Vaish, A., Carpenter, M., \& Tomasello, M. (2009). Sympathy through affective perspective-taking and its relation to prosocial behavior in toddlers. Developmental Psychology, 45, 534-543.

Warneken, F., \& Tomasello, M. (2006). Altruistic helping in human infants and young chimpanzees. Science, 311, 1301-1303.

Warneken, F., \& Tomasello, M. (2007). Helping and cooperation at 14 months of age. Infancy, 11(3), 271-294.

Warneken, F., \& Tomasello, M. (2008a). Roots of human altruism in chimpanzees. Primate Eye 96 (Special Issue: Abstracts of the XXII Congress of IPS, Edinburgh, UK), p. 16.

Warneken, F., \& Tomasello, M. (2008b). Extrinsic rewards undermine altruistic tendencies in 20-month-olds. Developmental Psychology, 44(6), 1785-1788.

Warneken, F., \& Tomasello, M. (2009a). Varieties of altruism in children and chimpanzees. Trends in Cognitive Sciences, 13(9), 397-402.

Warneken, F., \& Tomasello, M. (2009b). The roots of human altruism. British Journal of Psychology, 100, 455-471.

Yamamoto, S., Humle, T., \& Tanaka, M. (2009). Chimpanzees help each other upon request. PLOS ONE, 4(10), e7416. http://dx.doi.org/ 10.1371/journal.pone.0007416. 